\title{
Aqueous Extracts of Liriope platyphylla Are Tightly-Regulated by Insulin Secretion from Pancreatic Islets and by Increased Glucose Uptake through Glucose Transporters Expressed in Liver Hepatocytes
}

\author{
Ji Eun Kim ${ }^{1}$, So Hee Nam ${ }^{1}$, Sun II Choi ${ }^{1}$, In Sik Hwang ${ }^{1}$, Hye Ryun Lee ${ }^{1}$, Min Ju Jang ${ }^{2}$, Chung Yeol Lee ${ }^{1,2}$, \\ Hong Ju Soon ${ }^{1,2}$, Hee Seob Lee ${ }^{2,3}$, Hae Sung Kim ${ }^{4}$, Byeong Cheol Kang ${ }^{5}$, Jin Tae Hong ${ }^{6}$ \\ and Dae Youn Hwang ${ }^{1,2, *}$ \\ ${ }^{1}$ College of Natural Resources \& Life Science, ${ }^{2}$ Wellbeing Products RIS Center, Pusan National University, Miryang 627-706, \\ ${ }^{3}$ College of Human Ecollogy, Pusan National University, Busan 609-735, \\ ${ }^{4}$ College of Nanotechnology, Pusan National University, Miryang 627-706, \\ ${ }^{5}$ Department of Experimental Animal Research, Clinical Research Institute, Seoul National University Hospital, Seoul 110-744, \\ ${ }^{6}$ College of Pharmacy, Chungbuk National University, Chungju 361-763, Republic of Korea
}

\begin{abstract}
Liriope platyphylla is a medical herb that has long been used in Korea and China to treat cough, sputum, neurodigenerative disorders, obesity and diabetes. The aims of this study were to study the antidiabetic effects of the aqueous extract of $L$. platyphylla (AEtLP) through pancreatic and extrapancreatic actions. AEtLP were orally administrated to ICR mice once a day for 7 days. Of three different concentrations of AEtLP, only $10 \%$ AEtLP were low toxic to liver, based on body weight and serum biochemical analyses. However, 10\% AEtLP-treated mice displayed significant reduction of the glucose concentration and increased insulin concentration; no changes were noted using 5\% and 15\% AEtLP. Also, the increase of glucose transporter (Glut)- 1 expression in liver was dependent on the concentration of AEtLP, and was regulated by the phosphorylation of Akt. The lowest expression of Glut-3 was observed in 15\% AEtLP treated mice, followed by $10 \%$ AEtLP-and $5 \%$ AEtLP-treated mice. This pattern of Glut-3 expression was roughly in accord with the phosphorylation of c-Jun N-teminal kinase (JNK) in the mitogen-activated protein kinase (MAPK) pathway. Furthermore, a significant rise of the superoxide dismutase activity (SOD) was detected in AEtLP-treated mice. The findings suggest that AEtLP should be considered as a diabetes therapeutic candidate to induce insulin secretion from pancreatic $\beta$-cells and glucose uptake in liver cells.
\end{abstract}

Key Words: Liriope platyphylla, Insulin, Diabetes, Glucose transporter, Signaling pathway

\section{INTRODUCTION}

L. platyphylla is a perennial herb plant that is widely-distributed in temperate climate regions of the northern hemisphere. In Korea, these plants mainly grow mountainous regions at low altitude (i.e., $<500 \mathrm{~m}$ sea level) and their leaves remain green year-round (Huh et al., 2007). L. platyphylla has been the basis of a traditional oriental herbal medicine that has been long-used for the treatment of asthma and bronchial and lung inflammation (Lee et al., 2005). Data from several sciencebased studies has demonstrated the therapeutic effectiveness of the extract of the roots of L. platyphylla in the treatment of obesity, diabetes and neurodegenerative disease (Choi et al.,
2004; Hur et al., 2004; Jeong et al., 2008; Hur et al., 2009). Anti-inflamation and anti-microbial effects have been studied for a very long time. Kim et al. (2002) screened the extracts of many plants for anti-bacterial effects drugs via the detection of the inhibition of sortase (an enzyme found in most Gram-positive bacteria that is important in bacterial adhesion). Among 80 medical plants tested, L. platyphylla, Cocculus trilobus, Fritillaria verticillata, and Rhus verniciflua had strong anti-bacterial activity. Also, L. platyphylla potently inhibits airway inflammation and hyperresponsiveness in a murine model of asthma by modulating the relationship between Th1/Th2 cytokine imbalance (Lee et al., 2005) as well as atopic dermatitis induced by phthalic anhydride treatment (Kim et al., 2010a; 2010b). L. www.biomolther.org

Open Access DOI: 10.4062/biomolther.2011.19.3.348

pISSN: 1976-9148 elSSN: 2005-4483

Copyright $\odot 2011$ The Korean Society of Applied Pharmacology
Received Mar 31, 2011 Revised Jun 14, 2010 Accepted Jul 20, 2011

\footnotetext{
*Corresponding Author

E-mail: dyhwang@pusan.ac.kr

Tel: +82-51-350-5388, Fax: +82-51-350-5389
} 
platyphylla has also displayed therapeutic potential in human subjects suffering from Alzheimer's disease (AD). Especially, the steroidal saponin spicatoside A isolated from L. platyphylla induces neuritic outgrowth similar to nerve growth factor (NGF) and activation extracellular signal-regulated kinase 1/2 (ERK1/2) and phosphatidylinositol 3-kinase (PI3-kinase/Akt) in PC12 cells (Hur et al., 2009).

The potential of $L$. platyphylla in the treatment of obesity and diabetes has been reported (Choi et al., 2004; Jeong et al., 2008). The effects of Gyeongshingangjeehwan (mainly containing $L$. platyphylla) in preventing obesity and hypertriglyceridemia through the inhibition of feeding and the activation of hepatic peroxisome proliferator-activated receptoralpha in OLETF male rats was reported (Jeong et al., 2008). In another study, the homoisoflavone-enriched fraction of methanol extracts increased insulin-stimulated glucose uptake in 3T3-L1 adipocytes through increased glucose transporter (Glut)-4 contents in the plasma membrane (Choi et al., 2004). Recently, some novel compounds had been isolated from $L$. platyphylla using methanol extraction. Of these compounds, LP9M80-H was shown to induce insulin secretion and differentially regulate the expression of Glut-1 and Glut3 through the MAPK and phosphoinisitide-3-kinase (PI3-K) signaling pathways (Lee et al., 2011). However, the effects of aqueous extract isolated from $L$. platyphylla on diabetic ther- apy and verification of the mechanism in mice have not been described.

The present study demonstrates that AEtLP induces the upregulation of insulin secretion, and the downregulation of glucose concentration via the increase of the expression of several Glut proteins regulated by the insulin signaling pathway. The data presented here provide strong evidence of the potential of AEtLP in the prevention or alleviation of diabetesrelated disease.

\section{MATERIALS AND METHODS}

\section{Preparation of AEtLP}

L. platyphylla roots were collected from plantations in the Miryang area of Korea (Fig. $1 \mathrm{~A}$ and $\mathrm{B}$ ) and dried with a hotair drier (JSR Instruments, Uttaranchal, India) at $60^{\circ} \mathrm{C}$. The voucher specimens (WPC-11-010) were deposited at the Functional Materials Bank of PNU-Wellbeing RIS Center in Pusan National University. Six hundred grams of dry roots were reduced to powder using an electric blender. The water extract was purified at $100^{\circ} \mathrm{C}$ for $2 \mathrm{~h}$ using a circulated extraction equipment (IKA Labortechnik, Staufen, Germany) after adding $2 \mathrm{~L}$ of distilled water. The calories and composition of AEtLP were measured as described previously (Kim et
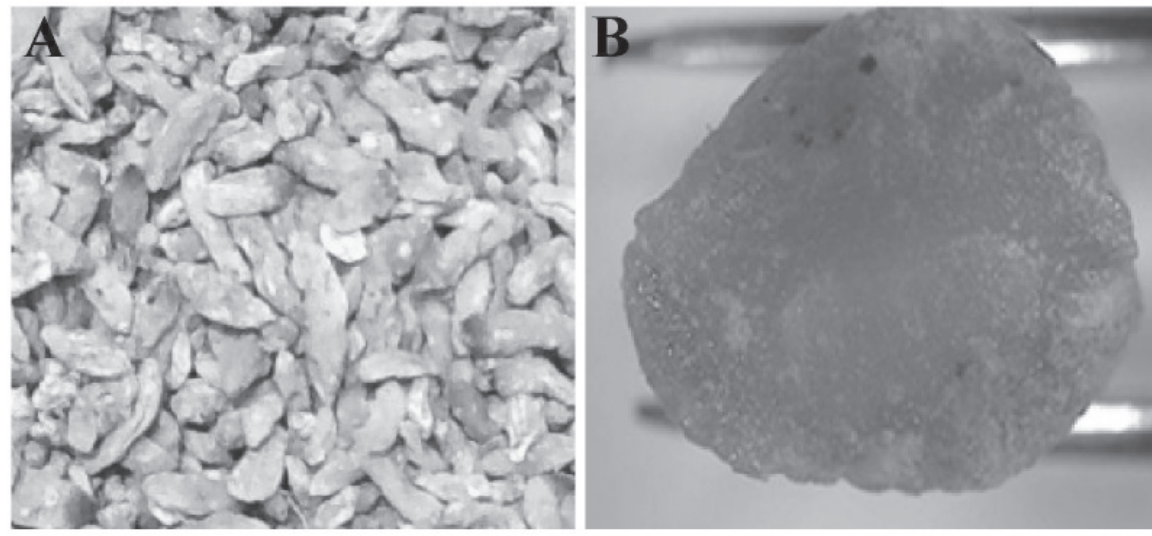

C

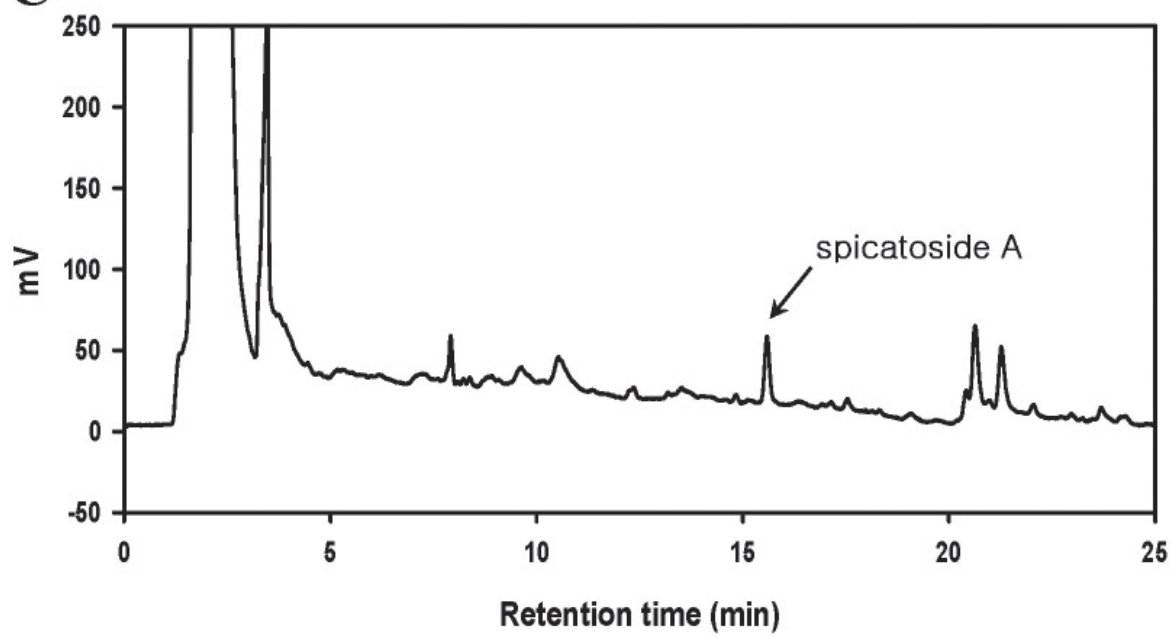

Fig. 1. Voucher specimen of Liriope platyphylla (A and B) and chromatogram of AEtLP. A cross section of Liriope platyphylla root used in this study was showed at Fig. 1B. 
al., 2001; 2010a). Extract solutions were concentrated into dry pellets using a rotary evaporator (EYELA, Tokyo, Japan) and stored at $-80^{\circ} \mathrm{C}$ until use.

\section{HPLC analysis of AEtLP}

The AEtLP was analyzed by iLC 3000 HPLC system (Interface Engineering, Seoul, Korea) equipped with Corona ${ }^{\circledR} \mathrm{CAD}^{\circledR}$ Detector (ESA Bioscinece, Inc., Chelmsford, MA, USA). The chromatographic separation was performed on a CAPCELL PAK MG C18 $(4.6 \times 250 \mathrm{~mm}$, particle size $5 \mu \mathrm{m}$, Shiseido Co. Ltd., Tokyo, Japan). The mobile phase consisted of solvent $A$ (deionized water) and solvent $B$ (acetonitrile) using the gradient elution program; $0-25 \mathrm{~min}, 30-90 \%$ of solvent $B$ and $25-40$ min, $90 \%$ of solvent B. A flow rate of $1.0 \mathrm{ml} / \mathrm{min}$ was used for the sample analysis. The nebulizer gas was compressed nitrogen. The gas flow rate and gas pressure were maintained at $1.53 \mathrm{~L} / \mathrm{min}$ and $35 \pm 2 \mathrm{psi}$, respectively. The output signal of the detector was recorded using a Clarity ${ }^{\mathrm{TM}}$ chromatography software (DataApex, Prague, The Czech Republic).

\section{Care and use of animals}

The animal protocol used in this study was reviewed and approved based on ethical procedures and scientific care by the Pusan National University-Institutional Animal Care and Use Committee (PNU-IACUC; Approval Number PNU2008-0056). Adult ICR mice were purchased from SamTacho (Osan, Korea) and handled at the Pusan National University Laboratory Animal Resources Center according to National Institutes of Health guidelines. All mice were given a standard irradiated chow diet (Purina Mills, Seoungnam, Korea) ad libitum, and were maintained in a specific pathogen-free state under a strict light cycle (light on at 06:00 $\mathrm{h}$ and off at 18:00 h) at a temperature of $22 \pm 2^{\circ} \mathrm{C}$ and at $50 \%$ relative humidity.

\section{Experimental design and measurement of blood glucose concentration}

Eight-week-old ICR mice $(n=28)$ were assigned to one of four groups ( $n=7$ per group): a vehicle-treated group, $5 \%$ AEtLP-treated group, 10\% AEtLP-treated group and 15\% AEtLP-treated group. The vehicle-treated group received a consistent volume of water daily via gavage (vehicle treated group), while the treatment groups received $15 \mu \mathrm{l} / \mathrm{g}$ body weight/day of AEtLP diluted in distilled water to obtain the three different final concentrations via gavage. At 7 days after commencement of AEtLp and vehicle treatment, all the animals were immediately sacrificed using $\mathrm{CO}_{2}$ gas to acquire blood and tissue samples, which were stored in Eppendorf tubes at $-70^{\circ} \mathrm{C}$ until assayed. In addition, the blood glucose concentration was detected prior to sacrifice and after $24 \mathrm{~h}$ of fasting using the sensitive strip of the Blood Glucose Monitoring System (I-sens, Seoul, Korea).

\section{Western blot}

Proteins from the tissues of the AEtLP-treated and vehicle-treated mice were separated by $4-20 \%$ sodium dodecyl sulfate-polyacrylamide gel electrophoresis (SDS-PAGE) for 3 $\mathrm{h}$ and the resolved proteins were transferred to nitrocellulose membranes for $2 \mathrm{~h}$ at $40 \mathrm{~V}$. Each membrane was incubated separately with the primary antibody: anti-Glut-1 (ab40084; Abcam, Cambridge, UK), anti-Glut-3 (ab15311; Abcam), ERK (sc-94; Santa Cruz Biotechnology, Santa Cruz, CA, USA), anti-phsophorylated p-ERK (sc-7383; Santa Cruz Biotechnol- ogy), anti-JNK (\#9252; Cell Signaling Technology, Boston, MA, USA), anti-p-JNK (\#9251, Cell Signaling Technology), anti-p38 (\#9212, Cell Signaling Technology), anti-p-p38 (\#9211, Cell Signaling Technology), anti-Akt (\#9272, Cell Signaling Technology), anti-p-Akt (\#4058, Cell Signaling Technology) and anti-actin (A5316, Sigma-Aldrich, Saint Louis, MO, USA) overnight at $4{ }^{\circ} \mathrm{C}$. The membranes were washed with a washing buffer $\left(137 \mathrm{mM} \mathrm{NaCl}, 2.7 \mathrm{mM} \mathrm{KCl}, 10 \mathrm{mM} \mathrm{Na}_{2} \mathrm{HPO}_{4}, 2 \mathrm{mM}\right.$ $\mathrm{KH}_{2} \mathrm{PO}_{4}$, and $0.05 \%$ Tween 20 ) and incubated with horseradish peroxidase-conjugated goat anti-rabbit lgG (Zymed Laboratories, South San Francisco, CA, USA) at a 1:1,000 dilution at room temperature for $2 \mathrm{~h}$. The membrane blots were developed using Chemiluminescence Reagent Plus kits (Pfizer, New York, NY, USA).

\section{Quantification of insulin by enzyme-linked immunosor- bent assay (ELISA)}

The concentration of insulin in the serum collected from the AEtLP-treated and vehicle-treated mice were determined using the ultra-sensitive assay procedure and reagents included in the Mice Insulin ELISA kit (\#10-1137-01, Mercodia, Uppsala, Sweden). The serum and standards were incubated in antibody-coated plates for $2 \mathrm{~h}$ at room temperature on a plate shaker at $500-600 \mathrm{rpm}$. The wells were then washed six times using a PV100 automatic plate washer (Hoefer, Holliston, MA, USA). The horseradish peroxidase (HRP) conjugates were added to all wells and incubated for $30 \mathrm{~min}$ at room temperature on a shaker. The reaction was terminated with the addition of $50 \mu \mathrm{l}$ of a stop solution. The alterations of color in the wells were read using a Vmax plate reader (Molecular Devices, Sunnyvale, CA, USA) at $450 \mathrm{~nm}$.

\section{Immunohistochemistry}

Immunohistochemical analysis was performed as previously described (Lee et al., 2011). Briefly, the distribution of insulin protein was observed using optical microscopy after fixing the tissue samples in $5 \%$ formalin for $12 \mathrm{~h}$, embedding the tissues in paraffin, and acquiring sections $4 \mu \mathrm{m}$ in thickness. Each section was de-paraffinized with xylene, rehydrated, and pretreated for $30 \mathrm{~min}$ at room temperature with a phosphate buffered saline (PBS)-based blocking buffer containing 10\% goat serum. The samples were then incubated with mouse anti-insulin antibody diluted 1:100-1:200 in PBS-blocking buffer. Antigen-antibody complexes were visualized with goat anti-rabbit HRP-conjugated streptavidin secondary antibody (Histostain-Plus Kit, Zymed Laboratories) diluted 1:1,500 in PBS-blocking buffer. 3,3'-Diaminodbenzidine (DAB) substrate (Invitrogen, Carlsbad, CA, USA) and a model GS-690 imaging densitometer (Bio-Rad Laboratories, Hercules, CA, USA) were used to detect insulin proteins.

\section{Activity analysis of superoxide dismutase (SOD)}

SOD activity in mouse erythrocytes was detected using the calorimetric assay procedure and the reagents in the BIOXYTECH SOD-525 kit (OxisResearch, Portland, OR, USA). The erythrocytes were harvested from the blood by centrifugation at 3,000 rpm for $10 \mathrm{~min}$ and then added to 4 volumes of cold deionized water in order to lyse the cells. The lysate was stored at $-70^{\circ} \mathrm{C}$ until it was used for the enzyme activity assay. To measure SOD activity, $900 \mu \mathrm{l}$ of reaction buffer (2-amino-2methyl-1, 3-propanediol, containing boric acid and DTPA, $\mathrm{pH}=8.8$ ) was aliquoted into test tubes for each blank 
or sample. Forty microliters of sample and $30 \mu \mathrm{l}$ of R2 reagent (1-methyl-2-vinylpyridinium trifluoromethanesulfonate in $\mathrm{HCl}$ ) were added to each tube and incubated at $37^{\circ} \mathrm{C}$ for 1 min. Thirty microliters of $\mathrm{R} 1$ reagent $(5,6,6 \mathrm{a}, 11 \mathrm{~b}$-tetrahydro$3,9,10$-trihydroxybenzo[c]fluorine in $\mathrm{HCl}$ ) was added to each

Table 1. Composition of Liriope platyphylla dry roots

\begin{tabular}{lc}
\hline Classification & Amount (per $100 \mathrm{~g})$ \\
\hline Calories & $28.16 \mathrm{kcal}$ \\
Carbohydrates & $6.89 \mathrm{~g}$ \\
Proteins & $0.06 \mathrm{~g}$ \\
Fat & $0.04 \mathrm{~g}$ \\
$\mathrm{Na}$ & $6.32 \mathrm{mg}$ \\
Saturated fat & $0.00 \mathrm{~g}$ \\
Trans fat & $0.00 \mathrm{~g}$ \\
Sugar & $0.37 \mathrm{~g}$ \\
Cholesterol & $0.00 \mathrm{mg}$ \\
\hline
\end{tabular}

test tube and vortexed briefly. The final mixture was immediately transferred to a spectrophotometric cuvette, and the absorbance was measured by a spectrophotometer at $525 \pm 2$ $\mathrm{nm}$. SOD activity was calculated directly from the experimental $\mathrm{Vs} / \mathrm{Vc}$ ratio using the follwing equation: $[\mathrm{SOD}]=0.93 \times(\mathrm{Vs} /$ Vc-1)/1.073-(0.073×(Vs/Vc)).

\section{Serum biochemical analysis}

After the final administration of AEtLP, all rats were fasted

Table 2. Composition of aqueous extracts isolated from Liriope platyphylla

\begin{tabular}{lc}
\hline \multicolumn{1}{c}{ Classification } & Amount $(\mathrm{g} / 100 \mathrm{ml})$ \\
\hline Total saponins & $0.056 \pm 0.01$ \\
Total soluble solid & $3.11 \pm 0.07$ \\
Total sugar & $1.59 \pm 0.08$ \\
Reducing sugar & $0.11 \pm 0.01$ \\
Total protein & $0.32 \pm 0.01$ \\
\hline
\end{tabular}

A

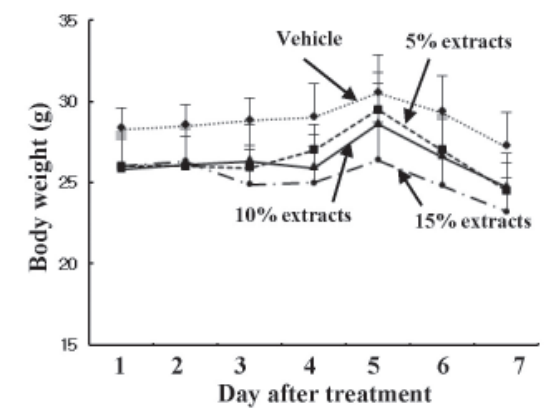

C

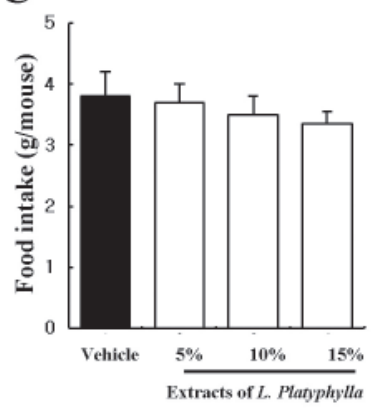

$\mathbf{F}$

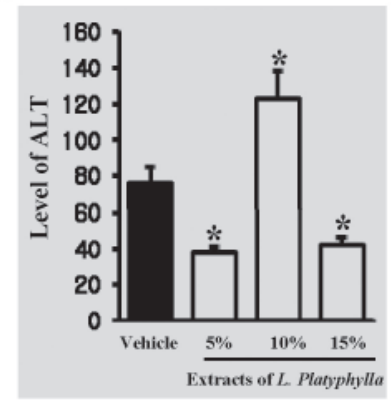

G
B

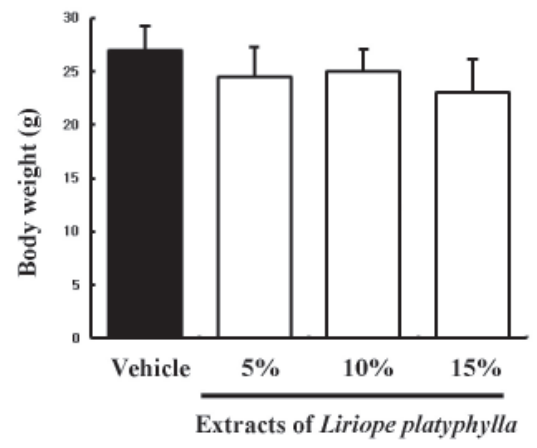

E
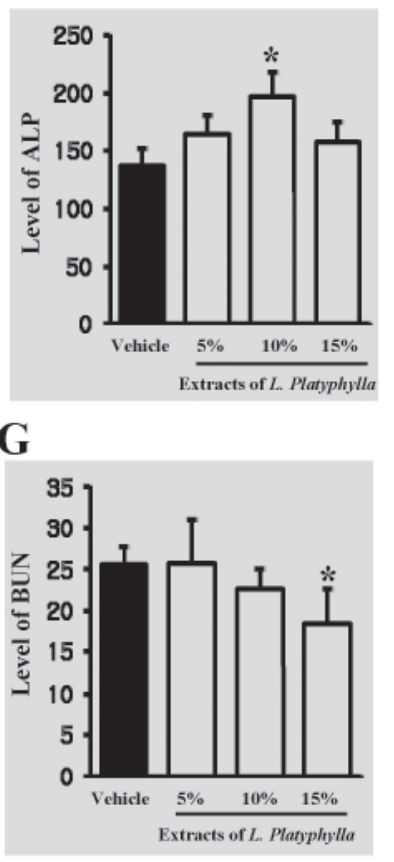

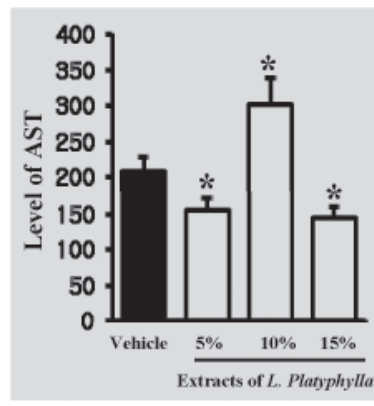

H

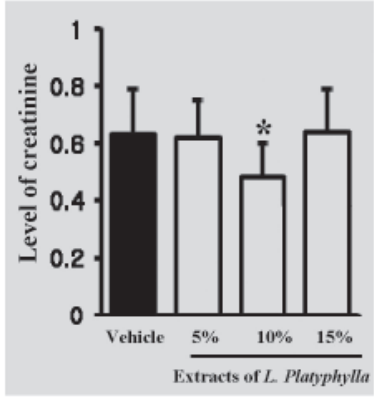

Fig. 2. Effects of of AEtLP on body weight of ICR mice. After AEtLP treatment, the body weight of ICR mice were measured with an electronic balance every day. (A) The weight fluctuation during 7 days was observed with the measuring body weight at every day. (B) Also, the body weight on the final day was immediately measured after euthanasia. (C) The average food intake was masured every day for 7 day. The concentration of ALP (D), AST (E), ALT (F), BUN (G) and creatinine $(H)$ in serum were analyzed in triplicate using serum biochemical analyzer as described in Materials and Methods. The data represents the mean \pm SEM from three replicates. ${ }^{*} p$ $<0.05$ is the significance level compared to the vehicle treated group. 
for $24 \mathrm{~h}$ and blood has collected from the abdominal vein. Serum was obtained by centrifugation of blood following incubation for $30 \mathrm{~min}$ at room temperature. Serum biochemical components were assayed using a model 747 automated serum analyzer (Hitachi, Tokyo, Japan). All assays were measured with fresh serum using standard enzymatic methods and conducted in duplicate.

\section{Statistical analysis}

One-way ANOVA (SPSS for Windows, Release 10.10, Standard Version; SPSS, Chicago, IL, USA) was used to determine whether significant differences existed between AEtLP-treated and vehicle-treated groups. All values are reported as the mean \pm SD. $p$-value of $<0.05$ was considered significant.

\section{RESULTS}

\section{Composition of AEtLP}

The dry roots of $L$. platyphylla consisted mainly of carbohydrates $(6.89 \mathrm{~g} / 100 \mathrm{~g})$ and sodium $(\mathrm{Na} ; 6.32 \mathrm{~g} / 100 \mathrm{~g})$, and, to much less extent, proteins, fat and sugar (Table 1). Saturated fat, trans-fat and cholesterol were absent. To quantify the concentration of the functional components in AEtLP, the concentrations of the major five items were analyzed using standard methods. Total saponins, a key component, represented $0.056 \mathrm{~g} / \mathrm{ml}$ of AEtLP. Of the other components, total soluble solid was greatest, followed by total sugar, total protein and reducing sugar (Table 2). Furthermore, HPLC chrogmatogram showed the level of spicatoside A which is one of the wellknown saponin contained in L. platyphylla (Fig. 1C).

\section{Effects of AEtLP on body weight and serum biochemical indicators}

To investigate the toxicity of AEtLP, the alteration of body weight and serum biochemical indicators were detected in ICR mice. No significant differences in body weight between the vehicle-treated group and AEtLP-treated group was evident over 7 days, although the body weight of of mice treated with the three different concentrations of AEtLP was slightly lower than that of vehicle-treated mice (Fig. 2A and B). Furthermore, to search for the cause of body weight decrease, the average food intake per day was measured in all groups. As shown Fig. $2 \mathrm{C}$, the pattern of food intake was very similar with the change of body weight. Therefore, these results suggested that the slight decrease of body weight could be induced by the decline of food intake per day. Also, the hepatotoxicity of AEtLP was observed as the measurement of alkaline phosphatase (ALP), alanine transaminase (ALT) and aspartate transaminase (AST) concentration. The ALP concentration was increased in all treated groups, although their increase rate was differented. The highest increase was observed in the 10\% AEtLP-treated group, followed 5\% AEtLP-treated group and $15 \%$ AEtLP-treated group (Fig. 2D). Moreover, other two indicators (ALT and AST) representing liver toxicity were
A

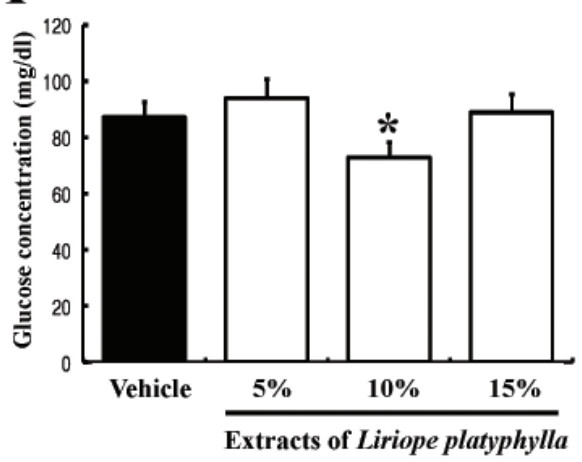

C

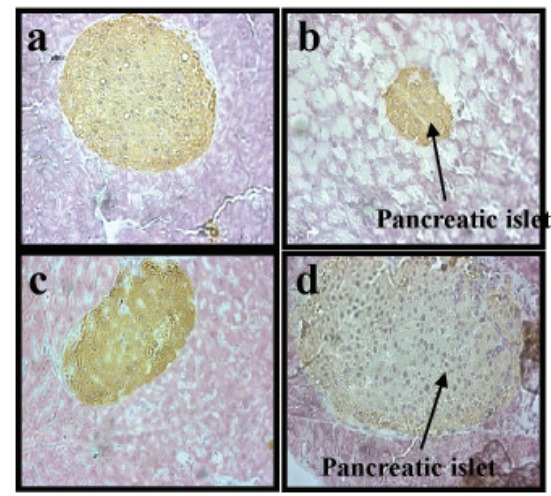

B
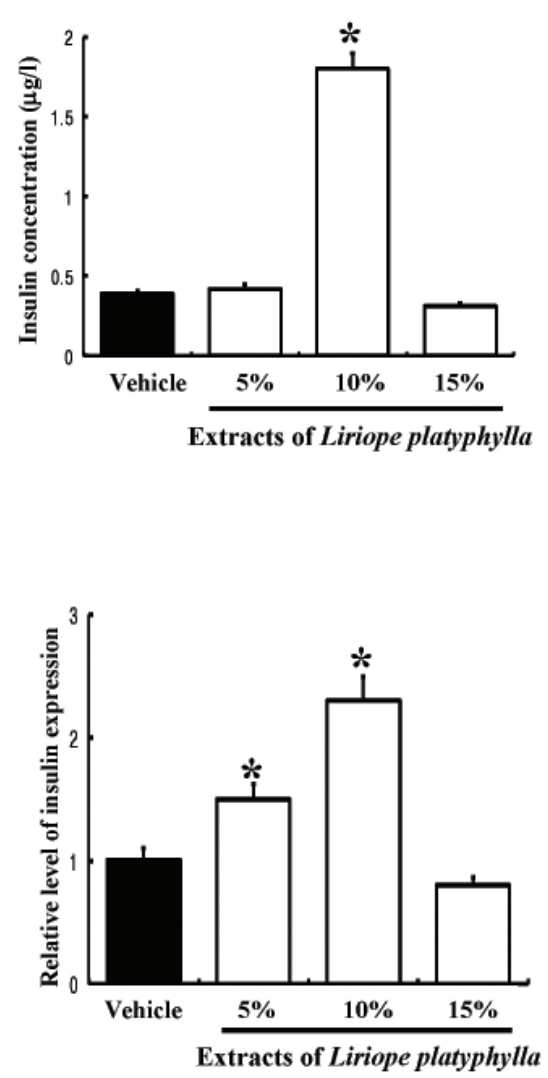

Fig. 3. Effects of AEtLP on blood glucose and insulin concentration (A and B). Blood was collected from the abdominal veins of the vehicletreated mice and AEtLP-treated mice. Glucose level was measured by a $\mathrm{Ca}$ reSence Kit and theinsulin level was determined using an insulin ELISA kit. (C) Immunostaining analysis for insulin expression. The expression level of insulin was detected in the pancreatic islets of vehicle-treated and AEtLP-treated mice by immunostaining analysis. A high intensity was observed in the pancreatic islets of the $10 \%$ AEtLP-treated mice as compared with the vehicle-treated mice at $200 x$ magnification. The data represents the mean \pm SEM from three replicates. ${ }^{*} p<0.05$ is the significance level compared to the vehicle treated group. 
showed a similar pattern after treatment of 3 type AEtLP. Of three groups treated with different concentration of AEtLP, the significant increase was observed in only $10 \%$ AEtLP-treated groups (Fig. 2E and F). However, the concentration of BUN and creatin which were represented the kidney toxicity were lower in all groups (Fig. $2 \mathrm{G}$ and $\mathrm{H}$ ). The results supported the suggestion that $10 \%$ concentrations of AEtLP were low toxic to the liver, although $5 \%$ and $15 \%$ AEtLP were nontoxic to the liver of mice. But, three concentration of AEtLP were nontoxic to the kidney of mice.

\section{Effects of AEtLP on insulin secretion and glucose homeostasis}

To ascertain whether AEtLP treatment affected the regulation of glucose metabolism, the serum concentrations of glucose and insulin were measured in AEtLP-treated and vehicle-treated mice after 7 days of treatment. The glucose concentration was significantly decreased in only mice treated with $10 \%$ AEtLP among the three different AEtLP concentrations. The glucose concentration in $5 \%$ and $15 \%$ AEtLP treated group were very similar with the vehicle-treated group (Fig. $3 A$ ). Insulin concentrations showed a reverse pattern to that of glucose concentrations. Of the AEtLP-treated groups, a significant increase of insulin concentration was evident only in mice treated with $10 \%$ AEtLP (Fig. 3B).

Also, to detect the localization and distribution of the insulin protein in pancreatic tissues, insulin protein immunoreactivity in the pancreas was analyzed using optical microscopy. The highest intensity of insulin immunostaining was evident spread throughout the pancreatic islets of $10 \%$ AEtLP-treated mice. Lower intensity was observed in 5\% AEtLP-treated mice. However, the $15 \%$ AEtLP-treated mice maintained the intensity level of insulin (Fig. $3 \mathrm{C}$ ). The results supported the suggestion that AEtLP treatment could induce the downregulation of glucose concentration through the stimulation of insulin secretion in ICR mice. Especially, in this regulation, 10\% AEtLP was more effective than the other concentrations on anti-diabetic effects.

\section{Effects of AEtLP on regulation of Glut-1 expression through the insulin signaling pathway}

The regulation of Glut-1 expression is tightly regulated by the PI3-K pathway including insulin receptor signaling (IRS), P110-p85, Akt and mTOR (Taha and Klip, 1999). Therefore, to study the regulation mechanism of Glut-1 expression via the insulin signaling pathway after AEtLP treatments, the alteration of Glut-1 expression and Akt phosphorylation were detected in the livers of mice treated with the three different concentrations of AEtLP. Glut-1 expression was markedly increased depending on AEtLP concentration. In 10\% AEtLPtreated mice, Glut-1 expression was significantly increased compared to vehicle-treated mice, while no change was noted in the 5\% AEtLP-treated group. Furthermore, in 15\% AEtLPtreated mice, the level of Glut-1 expression was markedly greater (about 64\%) than in 10\% AEtLP-treated mice (Fig. $4 \mathrm{~A}$ ). In addition, the level of Akt phosphorylation was significantly increased depending on the concentration of AEtLP. The highest level of Akt phosphorylation was detected in 15\% AEtLP-treated mice, followed 10\%- and 5\% AEtLP-treated groups (Fig. 4B). The results showed that AEtLP may induce the increase of Glut-1 expression via Akt phosphorylation in the insulin signaling pathway.
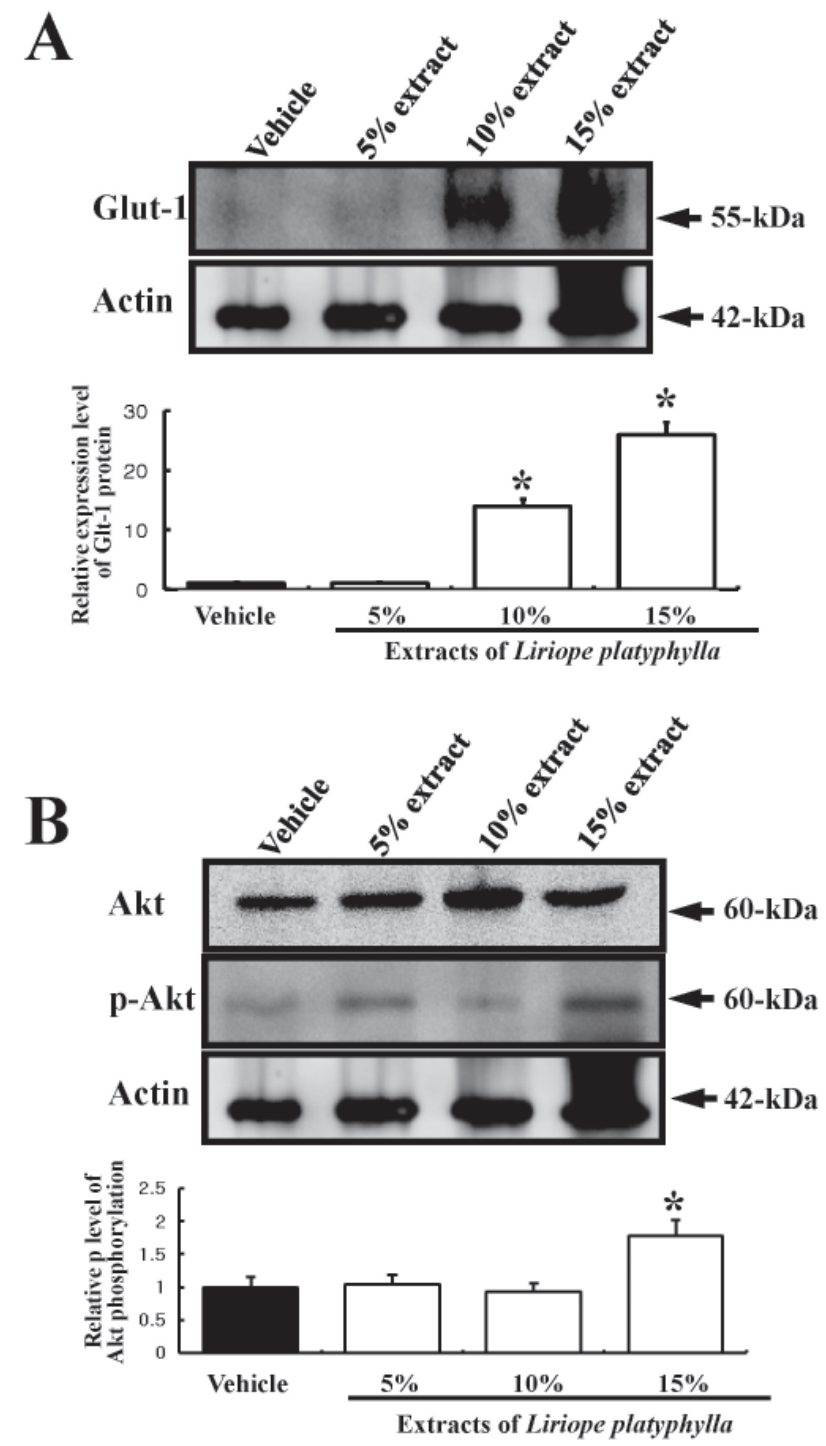

Fig. 4. Glut-1 expression and their regulation mechanism in liver Cell lysates were prepared from liver tissue of vehicle-treated mice and AEtLP-treated mice. Fifty micrograms of protein per sample were immunoblotted with antibody for each protein. Glut-1 protein expression was detected with anti-Glut-1 primary antibody and horseradise peroxidase-conjugated goat anti-rabbit lgG. The intensity of each protein was calculated using an imaging densitometer. The data represents the mean \pm SEM from three replicates. ${ }^{*} p<0.05$ is the significance level compared to the vehicle treated group.

\section{Effects of AEtLP on regulation of Glut-3 expression through the insulin signaling pathway}

The regulation of Glut- 3 biosynthesis can be regulated by the downstream signaling pathway of the insulin receptor, which includes Ras, Raf, MEK and MAPK (Taha and Klip, 1999). Of these intermediate proteins, MAPK, which is comprised of three major components, is considered crucial. To investigate the effect of AEtLP on the regulation mechanism and biosynthesis of Glut-3, the changes of Glut-3 protein and MAPK phosphorylation were analyzed using Western blot. The expression level of Glut-3 was absolutely dependent on 
the concentration of AEtLP. In 5\% AEtLP-treated mice, Glut3 expression was slightly lower than in vehicle-treated mice. Furthermore, 15\% AEtLP-treated mice showed a marked lowering of Glut-3 expression, compared to $10 \%$ AEtLP-treated mice (Fig. 5A and B). To identify the regulation mechanism of Glut-3 expression, the phosphorylation level of three components in MAPK pathway were detected in livers of mice. Of the MAPK pathway components, the phosphorylation level of ERK was markedly increased depending on the concentration of AEtLP. However, the phosphorylation level of JNK in the $10 \%$ AEtLP-treated group was the lowest of the three AEtLP treatment groups, and the phosphorylation level was slightly decreased in the $15 \%$ AEtLP-treated group. Lastly, no appreciable differences were evident between the vehicle-treated group and AEtLP-treated group concerning the expression of p38 and p-p38 (Fig. 5C and D). The results suggested that the expression level of Glut-3 was tightly correlated with the activiation of ERK phosphorylation under the condition of AEtLP treatment although their level was slightly correlated with the inhibition of JNK phsophorylation.

\section{Effects of AEtLP on liver SOD activity}

To investigate the effects of AEtLP on the anti-oxidant sta- tus of mice, SOD activity was determined in the erythrocytes of vehicle- and AEtLP-treated mice. In analyses using a high concentration of protein, AEtLP-treated mice displayed a higher rate of SOD activity than the vehicle-treated mice. Especially, in the assay using $50 \mu \mathrm{g}$ protein, the activity of SOD was greatly increased in 5\% AEtLP-treated mice compared to the other groups, while being only slightly increased in the $10 \%$ and $15 \%$ AEtLP-treated groups. These patterns of SOD activity were maintained in the assay using $10 \mu \mathrm{g}$ protein. However, the significant change of SOD activity disappeared when $2 \mu \mathrm{g}$ or $1 \mu \mathrm{g}$ protein was used in the assays (Fig. 6). The results implicated AEtLP as a contributor to the increase of SOD activity in the erythrocytes of mice at the high concentration of protein.

\section{DISCUSSION}

Diabetes, which is characterized by abnormal insulin regulation, derangement in lipid and carbohydrate metabolism, is one of the major worldwide health problems (Atalay and Laaksonen, 2002). Generally, this disease is diagnosed by the presence of hyperglycemia and markedly increased cardiovascular mortality and serious mobidity related to develop-
A

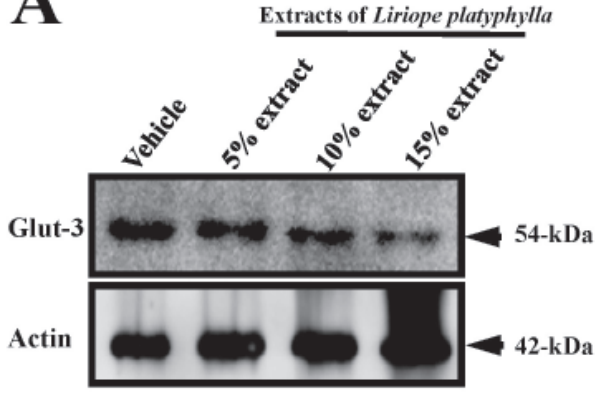

C

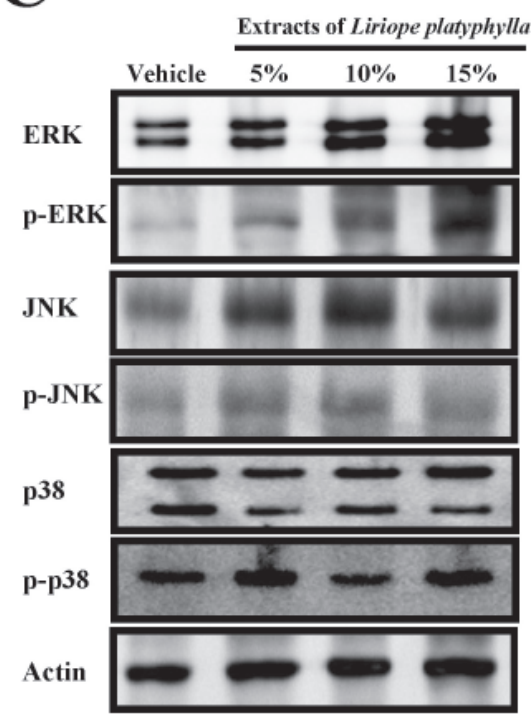

B

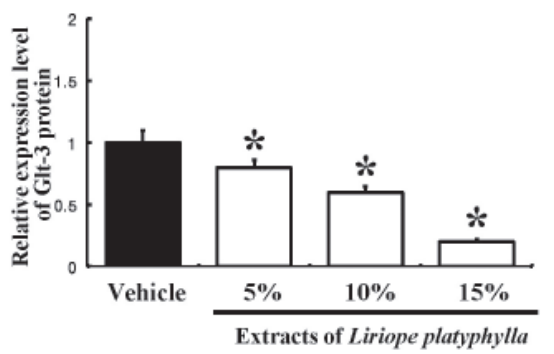

D
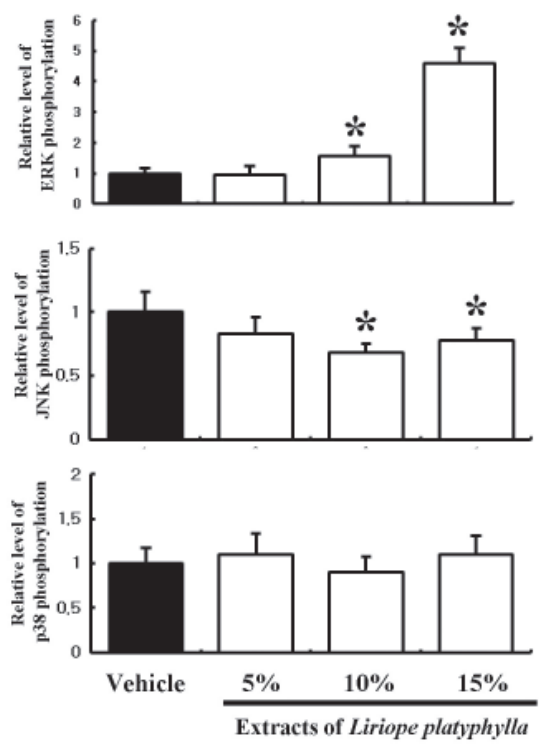

Fig. 5. Glut-3 expression and their regulation mechanism in liver. Fifty micrograms of the protein per sample were immunoblotted with antibody for p-ERK, ERK, p-JNK, JNK, p-38, p-p38 or actin. Three experiments were assayed in triplicate using Western blotting. The values are mean $\pm S D$. ${ }^{*} p<0.05$ is the significance level compared to the vehicle treated group. 


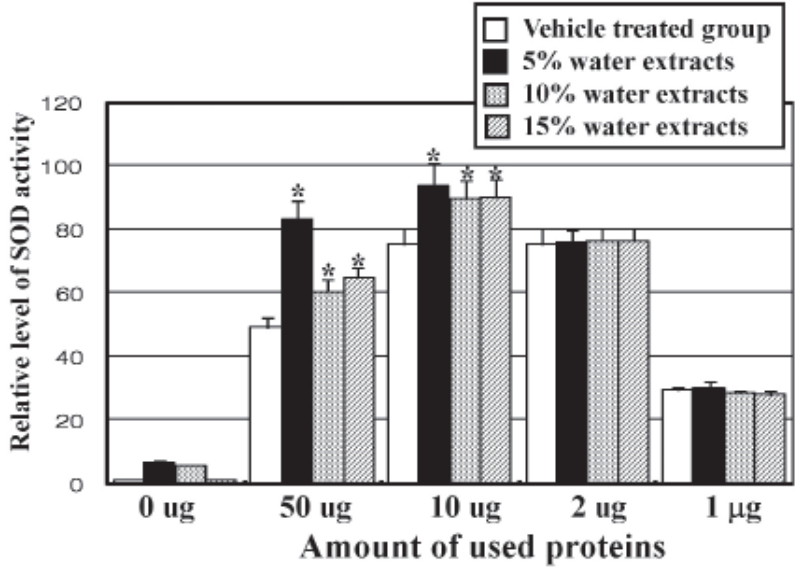

Fig. 6. Effects of of AEtLP on SOD activity. The liver tissues used in this assay were collected from the vehicle-treated and AEtLPtreated mice. Five rats per group were assayed in the SOD activity test. The data represents the mean \pm SEM from three replicates. ${ }^{*} p<0.05$ is the significance level compared to the vehicle treated group.

ment of nephropathy, retinopathy and neuropathy (Zimmet et al., 1997). Of two types of diabetes, Type 2 (noninsulin-dependent diabetes mellitus) accounts for $>90 \%$ of cases. Type 2 diabetes is characterized by resistance to insulin action on glucose uptake in peripheral tissue, impaired action of insulin to inhibit hepatic glucose production and dysregulated insulin secretion (Kahn, 1998). To identify novel drugs for treatment of diabetes, many compounds isolated from medical plants have been investigated as insulin regulators. Of these medical plants, $L$. platyphylla has the potential to be developed for therapy eutic ddiabetes and obesity, based on the results of efficacy testing (Choi et al., 2004; Lee et al., 2011). The present results add to the weight of evidence supporting the therapeutic potential of $L$. playphylla, and AEtLP in particular, as a novel therapeutic drug.

Some drugs have been developed to treat type 2 diabetes patients. Troglitazone, which was originally discovered from a Japanese plant, was approved as the first drug to reduce insulin resistance. The basis of action iseither enhancement of insulin action or mimicking of insulin's action; troglitazone does not affectinsulin secretion from $\beta$-pancreatic cells (Kreagen et al., 1989; Iwanishi and Kobayash, 1993). However, troglitazone can severely affect the liver of the treated animal. Aside from troglitazone, several other plant compounds have been reported as insulin sensitizers. In one study, an extract of Polygonatum odoratum Druce was demonstrated to have an anti-hyperglycemic effect by promoting insulin sensitivity (Choi and Park, 2002). In another study, a homoisoflavoneenriched fraction with an insulin sensitizing effect was initially extracted from $L$. platyphylla with $70 \%$ ethanol and sequentially separated with Diaion HP-20 and silica gel column chromatography (Choi et al., 2004). Sulfuretin, one of the main flavonoids of Rhus vernicilua, can completely prevent the hyperglycemia and hypoinsulinemia induced by streptozotocin (Song et al., 2010). Especially, some aqueous extracts display anti-diabetic activity. In one study, the aqueous extract of Mours rubra L. leaves demonstrated a dose-dependent fall in glucose concentration. Also, treatment with $400 \mathrm{mg} / \mathrm{kg}$ of the extract induced the significant reduction in glycosylated hemoglobin and restored the altered serum lipid level (Sharma et al., 2010). The aqueous extract of Cassia auriculata leaves was shown to improve impaired glucose homeostasis by ameliorating the carbohydrate metabolic pathways (Gupta et al., 2010). Presently, aqueous extracts were obtained from dried roots of $L$. platyphylla and three extract concentrations were screened for their effect on diabetes and obesity. Of the three concentrations, $10 \%$ AEtLP effectively induced the downregulation of glucose concentration and upregulation of insulin concentration. However, the regulation of glucose and insulin concentration was not depended on the concentration of AEtLP. Especially, the concentration of glucose and insulin in the groups treated with $15 \%$ AEtLP was very similar to that level in vehicle and 5\% AEtLP-treated group. Meanwhile, the toxicity analysis also showed that $10 \%$ AEtLP treatment could induce the liver toxcicity, while other two concentration of AEtLP could not induce the significant liver toxicity. These results were distincted from the common features drawn from the test to measure the efficay using medical herb. But, we assumed that the high concentration of insulin induced by $10 \%$ AEtLP treatment may promote the overactivation of liver, and this activation can consider one of the leading cuase of insulin down-regulation and liver toxicity. Therefore, additional studies will be needed to verify the detail mechanism of this theologically possibility. Nevertheless, our results implicate 10\% AEtLP as being optimal for diabetes therapy.

Glucose transporter ferries glucose and related hexose molecules through biological membranes according to a model of alterate conformation (Oka et al., 1990). Of these transporters, the biosynthesis of Glut- 1 and Glut- 3 was specifically regulated by the insulin signaling pathway in the liver; Glut-1 by the PI3-K pathway and Glut-3 by the Raf/Ras/MAPK pathway. In the PI3-K pathway, Akt (protein Ser/Thr kinase B), which plays an important role in cell proliferation and insulin action in cells, is activated by PDK1 (Roith and Zick, 2001). Activated Akt has been implicated in regulating the biosynthesis of Glut-1, a high-affinity glucose transporter expressed in most types of cells (Czech and Corvera, 1999). In this study, the biosynthesis of Glut-1 in mouse liver was markedly increased depending on the concentration of AEtLP. This alteration coincided with the change of Akt phosphorylation. Therefore, AEtLP may induce the overexpression of Glut-1 through Akt phosphorylation in order to downregulat the glucose level in blood. However, in the case of $15 \%$ AEtLP treatment, the high expression of Glut-1 did not exactly match the degree of the downregulation of glucose. The reason(s) remain unclear and require study. In addition, Glut-3 biosynthesis is mediated by the Raf/Ras/MAPK pathway to regulate glucose uptake (Taha and Klip, 1999). In this pathway, the MAPK kinase pathway is activated by the binding of Grb2 to Tyr-phosphorylated Shc or IRS via its $\mathrm{SH} 2$ domain. Finally, this signal leads to the expression of genes associated with glucose metabolism and the induction of mitosis in cells (Roith and Zick, 2001). As shown in Fig. 5, the biosynthesis of Glut-3 in liver was significantly decreased by the treatment of all three concentrations of AEtLP. Also, these regulation patterns corresponded with the activation of ERK phosphorylation more so than the phosphorylation of JNK and p38. Ras-Raf-ERK signal transduction cascade was firstly discovered as a large network of signaling protein to perform their cellular programs after growth factor treatment. Of three MAPK signaling pathways, the ERK 
phosphorylation cascades have been known to consider as important factor in intracellular signaling. Also, this pathway was involved to cascade process in cellular proliferation, differentiation and survival, and its inappropriate activation was also founded in human cancers (Pages et al., 1999). Our data firstly suggested that the expression of Glut-3 may be more affected by the hyperactivation of ERK phosphorylation than the inhibition of JNK phosphorylation.

Taken together, our results provide a detailed mechanism of for the anti-diabetic activity of AEtLP in the liver of mice. AEtLP can for the present be considered a potential therapeutic candidate for diabetes.

\section{ACKNOWLEDGMENTS}

This research was supported by a grant to PNU-Wellbeing Product Center from the Ministry of Knowledge Economy (B0011529).

\section{REFERENCES}

Atalay, M. and Laaksonen, D. E. (2002) Diabetes, oxidative stress and physical exercise. J. Sports Sci. Med. 1, 1-14

Choi, S. B. and Park, S. (2002) A steroidal glycoside from Polygonatum (Mill.) odoratum Druce improves insulin resistance but does not alter insulin secretion in $90 \%$ pancreatectomized rats. Biosci. Biotech. Biochem. 66, 2036-2043.

Choi, S. B., Wha, J. D. and Park, S. (2004) The insulin sensitizing effect of homoisoflavone-enriched fraction in Liriope platyphylla Wang et Tang via PI3-kinase pathway. Life Sci. 75, 2653-2664.

Czech, M. P. and Corvera, S. (1999) Signaling mechanisms that regulate glucose transport. J. Biol. Chem. 274, 1865-1868.

Gupta, S., Sharma, S. B., Singh, U. R., Bansal, S. K. and Prabhu, K. M. (2010) Elucidation of mechanism of action of Cassia auriculata leaf extract for its antidiabetic activity in streptozotocin-induced diabetic rats. J. Med. Food. 13, 528-534.

Huh, M. K., Huh, H. W., Choi, J. S. and Lee, B. K. (2007) Genetic diversity and population structure of Liriope platyphylla (Liliaceae) in Korea. J. Life Sci. 17, 328-333.

Hur, J., Lee, P., Kim, J., Kim, A. J., Kim, H. and Kim, S. Y. (2004) Induction of nerve growth factor by a butanol fraction of Liriope platyphylla in $\mathrm{C} 6$ and primary astrocyte cells. Biol. Pharm. Bull. 27, 1257-1260.

Hur, J., Lee, P., Moon, E., Kang, I., Kim, S. H., Oh, M. S. and Kim, S. Y. (2009) Neurite outgrowth induced by spicatoside A, a steroidal saponin, via the tyrosine kinase A receptor pathway. Eur. J. Pharmacol. 620, 9-15.

Iwanishi, M. and Kobayash, M. (1993) Effects of pioglitazone on insulin receptors skeletal muscle from high-fat-fed rats. Metabolism 42, 1017-1021.

Jeong, S., Chae, K., Jung, Y. S., Rho, Y. H., Lee, J., Ha, J., Yoon, K. H., Kim, G. C., Oh, K. S., Shin, S. S. and Yoon, M. (2008) The Ko- rean traditional medicine Gyeongshingangjeehwan inhibits obesity through the regulation of leptin and PPARalpha action in OLETF rats. J. Ethnopharmacol. 119, 245-251.

Kahn, N. N. (1998) Insulin-induced expression of prostacyclin receptors on platelets is mediated through ADP-ribosylation of $\mathrm{Gi}$ alpha protein. Life Sci. 63, 2031-2038.

Kim, H. J., Kim, J., Kim, S. J., Lee, S. H., Park, Y. S., Park, B. K., Kim, B. S., Kim, S. K., Cho, S. D., Jung, J. W., Nam, J. S., Choi, C. S. and Jung, J. Y. (2010b) Anti-inflammatory effect of quercetin on picryl chloride-induced contact dermatitis in BALB/c mice. Lab. Anim. Res. 26, 7-13.

Kim, J. E., Lee, Y. K., Nam, S. H., Choi, S. I., Goo, J. S., Jang, M. J., Lee, H. S., Son, H. J., Lee C. Y. and Hwang, D. Y. (2010a) The symptoms of atopic dermatitis in NC/Nga mice were significantly relieved by the water extract of Liriope platyphylla. Lab. Anim. Res. 26, 377-384.

Kim, S. D., Ku, Y. S., Lee, I. Z., Kim, I. D. and Youn, K. S. (2001) General components and sensory evaluation of hot water extract from Liriopis Tuber. J. Korean Soc. Food Sci. Nutr. 30, 20-24.

Kim, S. W., Chang, I. M. and Oh, K. B. (2002) Inhibition of the bacterial surface protein anchoring transpeptidase sortase by medicinal plants. Biosci. Biotechnol. Biochem. 66, 2751-2754.

Kreagen, E. W., James, D. E. and Jenkins, A. B. (1989) A potent in vivo effect of ciglitazone on muscle insulin resistance induced by high fact feeding of rats. Metabolism 38, 1089-1093.

Lee, Y. C., Lee, J. C., Seo, Y. B. and Kook, Y. B. (2005) Liriopis tuber inhibits OVA-induced airway inflammation and bronchial hyperresponsiveness in murine model of asthma. J. Ethnopharmacol. 101, 144-152.

Lee, Y. K., Kim, J. E., Nam, S. H., Goo, J. S., Choi, S. I., Choi, Y. H., Bae, C. J., Woo, J. M., Cho, J. S., and Hwang, D. Y. (2011) Differential regulation of the biosynthesis of glucose transporters by the PI3-K and MAPK pathways of insulin signaling by treatment with novel compounds from Liriope platyphylla. Int. J. Mol. Med. 27, 319-327.

Oka, Y., Asano, T., Shibasaki, Y., Lin, J., Tsukuda, K., Katagiri, H., Akanuma, Y., and Takaku, F. (1990) C-terminal truncated glucose transporter is locked into an inward-facing form without transport activity. Nature 345, 550-553.

Pages, G., Guerin, S., Grall, D., Bonino, F., Smith, A., Anjuere, F., Auberger, P. and Pouyssegur, J. (1999) Defective thymocyte maturation in p44 MAP kinase (Erk 1) knockout mice. Science 286, 13741377.

Roith, D. L. and Zick, Y. (2001) Recent advances in our understanding of insulin action and insulin resistance. Diabetes Care 24, 588-597.

Sharma, S. B., Gupta, S., Ac, R., Singh, U. R., Rajpoot, R., and Shukla, S. K. (2010) Antidiabetogenic action of Morus rubra L. leaf extract in streptozotocin-induced diabetic rats. J. Pharm. Pharmacol. 62, 247-255.

Song, M. Y., Jeong, G. S., Kwon, K. B., Ka, S. O., Jang, H. Y., Park, J. W., Kim, Y. C., and Park, B. H. (2010) Sulfuretin protects against cytokine-induced beta-cell damage and prevents streptozotocininduced diabetes. Exp. Mol. Med. 42, 628-638.

Taha, C. and Klip, A. (1999) The insulin signaling pathway. J. Membrane Biol. 169, 1-12

Zimmet, P. Z., McCarty, D. J., and de Courten, M. P. (1997) The blobal epidemiology of non-insulin-dependent diabetes mellitus and the metabolic syndrome. J. Diabetes Complicat. 11, 60-68. 